\title{
The Study of Flipped Classroom Teaching Model Based on Guidance and Study Synchronous Double Helix
}

\author{
Chongyan Zhong ${ }^{1, a}$ and Liguo Wang ${ }^{1, b^{*}}$
}

${ }^{1}$ School of Information Technology and Media, Beihua University, Jilin, China, 132013

a1601520162@qq.com,bwlg7705@163.com

*The corresponding author

\begin{abstract}
Keywords: Flipped classroom; Teaching model; Guidance study synchronization; Educational theory; Application consideration
\end{abstract}

\begin{abstract}
Flipped classroom is the informationization product in educational environment of information age. After it absorbs the essence of the traditional education, it will make the education thrive and abound. Flipped classroom, comes from abroad, is in line with the development of our country's education. However, we don't have enough experience in reasonable control class time and carry out teaching activities. In this paper, on the basis of summarizing the shortcomings of the existing flipped classroom teaching model, combined with specific theoretical guidance, we creatively build a flipped classroom teaching model -- Guide and Study Synchronous Double Helix. Then this article describes the teacher activities and student activities carried out simultaneously from macroscopic and microscopic two aspects. It is the common progress of bilateral activities at the same time and space; both sides are closely related to each other. This model detailed analysis the five parts of "Guidance and Study Synchronous Double Helix" flipped classroom teaching model of teaching activities. Finally, this article analyzes the current application of flipped classroom and provides some suggestions. Hope to provide reference for the educational practitioners and the scholars who further study the flipped classroom.
\end{abstract}

\section{Introduction}

The core idea of the flipped classroom is that readjusts the inside and outside class time, give students the initiative to learn. Outside class is the place of knowledge transfer. Students learn simple teaching content by watching the teaching video, then, complete online test and participate in online discussion and communication. Inside class is the place where knowledge is internalized. FAQ, collaborative learning, discussion and communication, and evaluation feedback through the teachers and students or between students. Flipped classroom emphasis on students as the center, teachers play a leading role. It pays attention to the process of knowledge internalization. It is the product of information age education in the field of information.

The application of the flipped classroom teaching mode can be traced back to 2007. Two chemical teachers in the United States Colorado Rocky Mountain Woodland Park High School Jonathan Bergmann and Aaron Sam's released the recorded video to the network for the students who sick and absences to use. The video not only received praise by the absent students, but also provide the resources to other students to review and strengthen the study. In view of this, they began to try to turn the classroom teaching mode.

Salman Khan in the "technology, entertainment, design" (TED) Conference on the "Let us use video reeducation" of the keynote speech in 2011, detailed analysis of the flipped classroom teaching mode. Since then, it has caused great concern of the educational circles to the new teaching mode.

\section{The Analysis of Classic Flipped Classroom Teaching Model}

The scholars at home and abroad have paid great attention to the flipped classroom in recent years. They put forward a lot of flipped classroom teaching mode, for example: 
Jackie Gerstein constructed the four stage model of ring turning classroom, as shown in Fig. 1. The four stages is the experience participation, the concept exploration, the significance construction and the demonstration application, and the four stages are clockwise. Teaching activities from the perspective of students, but the specific implementation of the process is not a clear explanation; the reference value is not strong.

Robert Talbert proposed the "Before class and during class" teaching structure model, as shown in Fig. 2. This model is proposed on the basis of summarizing the teaching experience of "linear algebra" course for many years. It combined with the characteristics of learners, and the design of each step of the flipped classroom is progressive. However, this model was originally designed for science courses. It has some limitations in designing other subjects turning over the course, which cannot provide a good basis for the design of other subjects.

Flipped classroom teaching model proposed by Wang Hong and other teachers in Northeast Normal University, as shown in Fig. $3^{[1]}$. Based on Robert Talbert's flipped classroom teaching model, it emphasizes the importance of information technology in the whole teaching activities. This model further refines all aspects of the class before and during the course. And it will run through the learning activities before class and during class in various links. However, there is no detailed description of the specific teaching strategies in the learning activities.

The Tai Chi ring flipped classroom model of Zhong Xiaoliu and other teachers design in Tsinghua University, as shown in Fig. 4[2]. This model is put forward in the background of some scholars who have too much emphasis on the "learning" of the students while ignoring the "teaching" of the teachers. Therefore, the model is biased in the teacher's "teaching", mainly reflects the teaching idea.

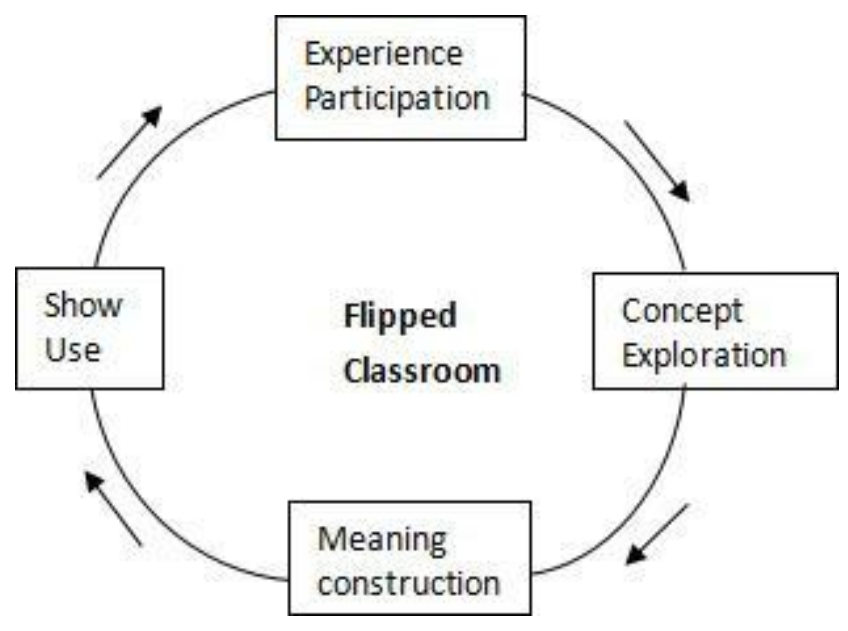

Figure 1. Ring four stage model

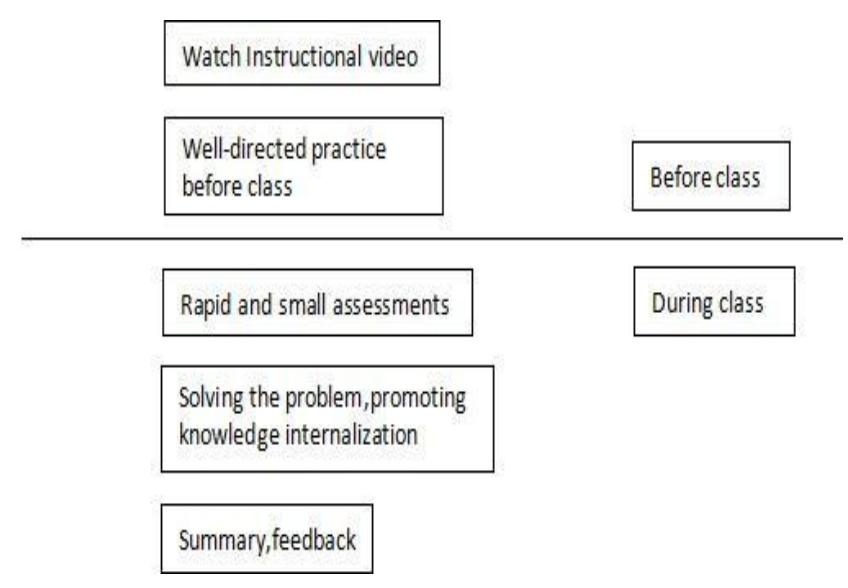

Figure 2. Before and during class model 


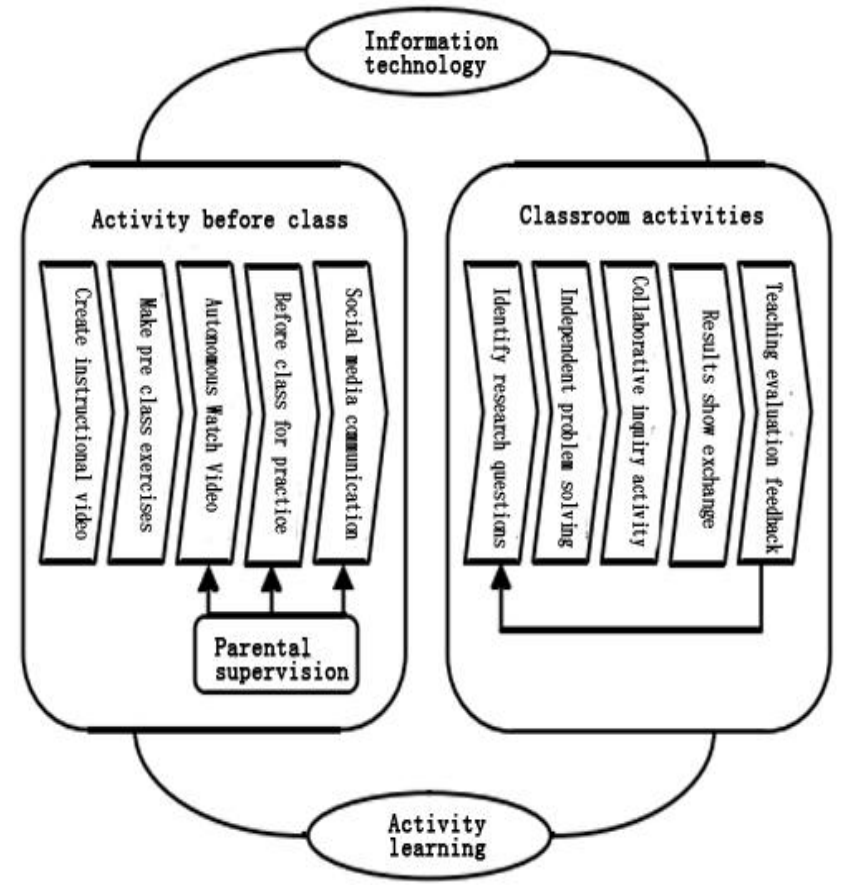

Figure 3. Flipped classroom teaching model

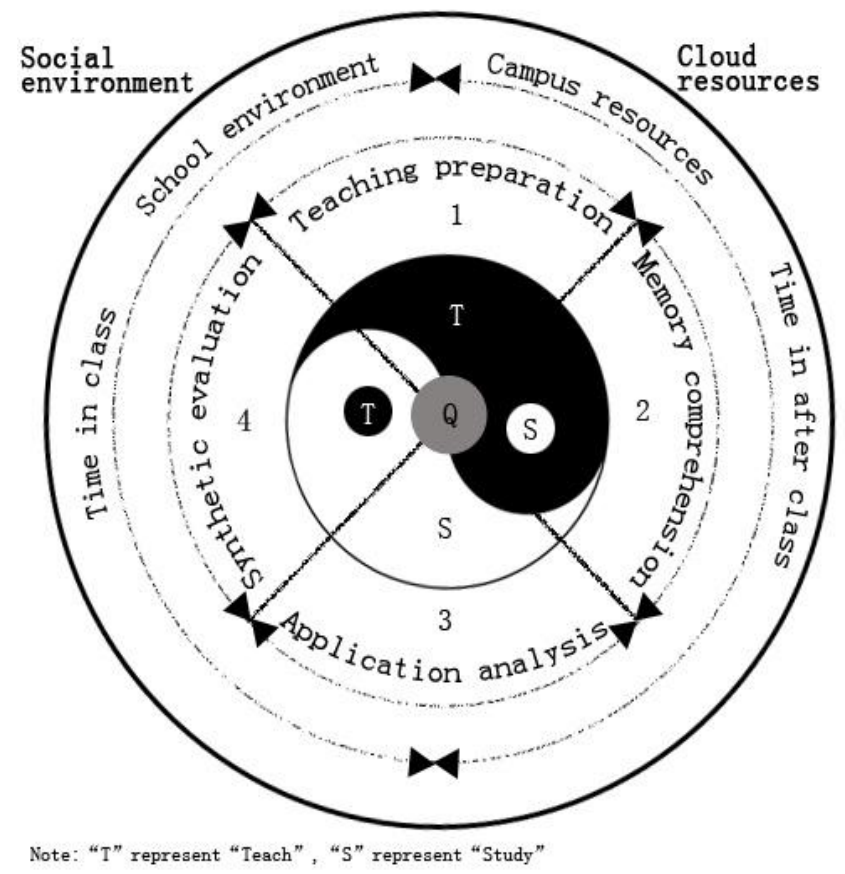

Figure 4. Tai Chi ring model

These proposed teaching models play a positive role in promoting the development of the flipped classroom, but the flipped classroom teaching mode still needs to be improved. In this paper, by analyzing the model of the flipped classroom teaching, combining teaching theory knowledge, on the basis of the improvement of these models, it put up a "Guidance and Study Synchronous Double Helix" flipped classroom teaching model.

\section{The Building of Flipped Classroom Teaching Model Based on "Guidance and Study Synchronous Double Helix"}

The activities of teachers and students should be bilateral interaction. Teachers can understand the students in a timely manner. Students encounter difficulties can be resolved in a timely manner. The relationship between teachers and students activities should be closely related to each other. Inspired by the "double helix" structure of DNA,this paper put up a "Guidance and Study Synchronous Double Helix" flipped classroom teaching model, as shown in Fig. 5(Macroscopic). This model takes the activities of teachers and students as two main chains. It contains five pairs of major elements. Each pair of elements in the same plane is closely related to each other. And it does not change with time and space. "Guidance" in "Guidance and Study Synchronous Double Helix" flipped classroom teaching model, means teacher answer the student's questions, organize and guide the students to carry out activities, help students with difficulty, detect evaluation and provide feedback in time. "Learning" means students use the network learning platform as a tool, with the help of micro video and other learning resources, they completes autonomous learning task list. So that the class learning and extra-curricular learning to form a seamless connection. 


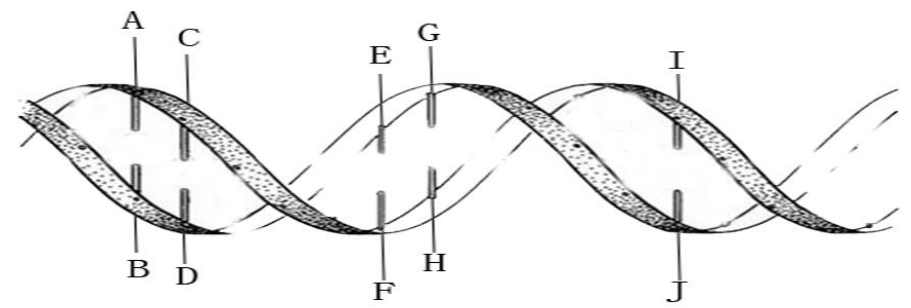
A.Analysis of teaching objectives
B.Learner characteristics
C.Task list
D.Autonomous Learning
E.Detection result
F.Solve the problem
G.Arrangement work
H.Internalized Knowledge
I.Evaluation summary
J.Feedback information

Figure 5. Flipped Classroom Teaching Model Based on "Guidance and Study Synchronous Double Helix" (Macroscopic)

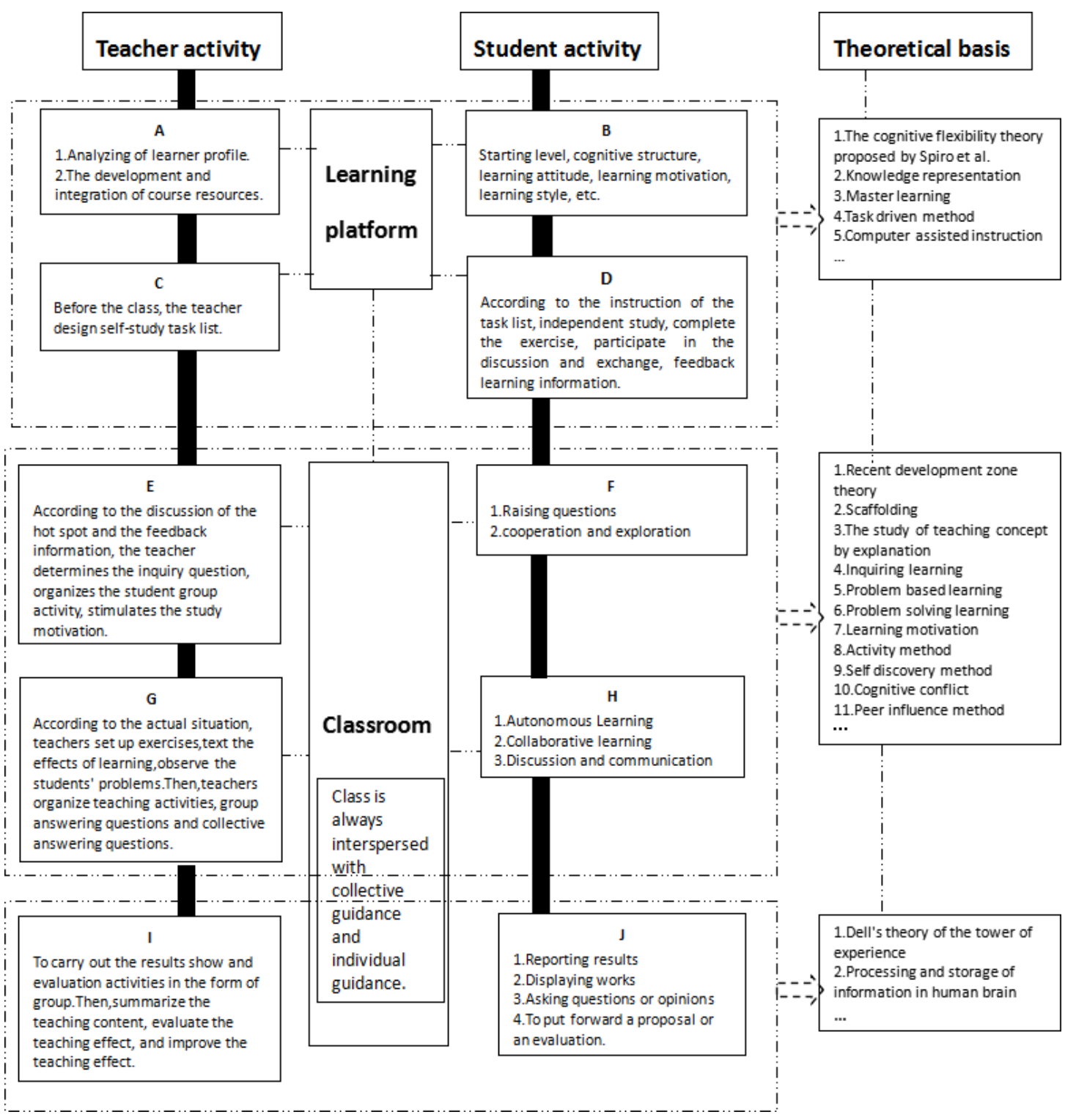

Figure 6. Flipped Classroom Teaching Model Based on "Guidance and Study Synchronous Double Helix" (Microcosmic)

Analysis of Teaching Objectives -- Learner Characteristics. The teaching goal is the guidance of all teaching behaviors, which is the basis of teaching resources, teaching strategies, teaching 
implementation and teaching evaluation. The preparation of teaching resources should be based on the teaching objectives, combined with the characteristics of learners, to maximize the integration of effective learning materials and exercises. At the same time, teachers can independently develop teaching resources, such as the production of PPT, micro video, etc. Students in the process of autonomous learning. First, understanding the background and meaning of the problem. And then putting forward the hypothesis to solve the problem, building the need to solve the problem, and then need to verify the assumptions related to the hypothesis. Only when the teaching resources are sufficient, the students can solve the problem and establish the related information resources. Teaching strategy selection should fully consider the teaching content suitable for the use of what kind of teaching methods, what kind of presentation to the professor. So that students better and faster to accept new knowledge, and ultimately to achieve teaching goals. According to the division of knowledge by Spiro et al, we should try our best to put the knowledge of good construction domain under the class. It will make the students easy to solve problems, and build a good self-confidence. Assigning the knowledge in the field of non-good construction to the class or as the research section, so when the students are confused, they can get help in time to get the sense of achievement. At the same time, the representation of the teaching content should be varied. According to the specific situation and the characteristics of learners to characterize the knowledge, to achieve personalized teaching ${ }^{[3]}$.

It is not practical to combine the analysis of teaching objectives with the characteristics of learners, which is of no practical value. Teachers should take full account of the student's current level of starting point, cognitive structure, learning attitude, learning motivation, learning style and so on. To analyses student's learning needs and learning behavior, pay more attention to and protect the student's learning interest and enthusiasm, take care of the students who study hard, do the best possible to achieve personalized teaching, realize teach students in accordance with their aptitude. The choice of teaching content should correspond to the characteristics of learners, it is not too difficult, and it cannot be too simple.

Task List -- Autonomous Learning. The task list includes four parts, the learning goal, the method prompts, the learning task and the feedback information. Pre class autonomous learning task list based on the teaching goal, we can get the goal of independent learning through the detailed teaching goal. The method prompts fully reflects the student's personalized learning. The teacher can design learning strategies for each student or suggest that students use some kind of method to study, so that students can achieve learning goals more easily and quickly. The arrangement of learning tasks, you can use the task driven teaching strategies. So that students take the goal of autonomous learning as the center in the network learning environment. In the drive of solving the problem and completing the task, take the initiative to the application of learning resources. Using mastery learning approach and computer assisted instruction, so that students in the autonomous learning micro video can be repeated to watch. Students Combines teaching materials and resources until the content is digested and absorbed. Then a small test can be carried out to develop the correct rate, if you meet the requirements, you can go through the customs clearance, if you do not meet the requirements will continue to learn, to re test(The test question is different from the last one, but it is the same.). Teacher counseling to help students online. The discussion and communication between teachers and students or between students carries out. And then students complete the practice. So that students produce teaching practice. Information feedback is a summary of the student's autonomous learning, which is advice to the teaching content and teaching activities, and the supplement of teaching resources and learning methods ${ }^{[4]}$.

In the process of autonomous learning, students are guided by the task of autonomous learning. Students find the knowledge, experience the pleasure of learning and love to learn. Students autonomous learning ability, self-management ability, problem-solving ability, rigorous thinking ability and other comprehensive ability have been improved. At the same time, parents should be involved in the process of student's autonomous learning. This not only helps students to learn to help, but also on the development of the flipped classroom and social recognition.

Detection Result -- Solve the Problem. Purpose of class testing: First, in order to detect the effect of students' autonomous learning; second is to enhance student's sense of achievement in learning and training, and to cultivate learning motivation. Through the students learning behavior, learning effect 
evaluation and discussion of communication on the network learning platform, teachers can determine the learning style in this class (Such as Simulation learning, inquiry learning, debate learning, collaborative learning, case study and other auxiliary models. ${ }^{[5]}$. For example, inquiry learning: With interlude collective guidance and individual guidance, organizing students to explore issues and carrying out the problem solving learning in the form of group collaboration ${ }^{[6]}$. In this process, teachers can not only understand the situation of students, but also can know the common problems and individual problems of students. Through constant "question -- evaluation -- feedback -- question", so that students will be better to be internalized into the cognitive structure ${ }^{[7]}$.

To integrate the students into the teaching activities designed by the teachers, learning motivation is the root ${ }^{[8]}$. Specifically speaking, teachers should improve belief on student's ability, and often encourage students. In the group learning process, the number of groups should not be more; teachers should ensure that all students get the challenge. When grouping, teachers should be based on different disciplines, different performance of team members to flexible grouping, or they can properly re grouping. Appropriate to give learning difficulties students tips or clues. And answer the question time is relatively abundant, and so on ${ }^{[9]}$.

Arrangement Work -- Internalized Knowledge. According to Piaget's theory of cognitive development, when individuals encounter new stimuli in the environment, the individual schema develops along the trend of "balance-imbalance-balance". This enriches the individual's cognitive structure, which is also the essence of the continuous improvement of individual intelligence. Take homework from after class to class, in accordance with the "evaluation feedback -- the arrangement of the operation -- evaluation feedback" loop, with interlude collective guidance and individual guidance. At the same time, it can eliminate the phenomenon of plagiarism. Trying to get the students to internalize the most of their knowledge, expand their capacity. Helping students to complete the re construction of knowledge structure. The teachers design homework, can follow the Vygotsky's Zone of Proximal Development, in order to stimulate student's potential. When the discussion activities, teachers can use some teaching methods based on Piaget's cognitive development theory (Such as activity method, self discovery method, cognitive conflict law and peer influence etc.). That will make the students to maximize the assimilation of knowledge, and ultimately to achieve a higher level of knowledge structure of the adaptation.

Students in the process of doing homework, teachers observe students to grasp the situation and the existing problems. In order to make the students further internalized knowledge, teachers should summarize the comprehensive problems, key problems and difficulties in the process of doing homework after the students finish their classroom work. Then, organizing the students to carry out learning activities. For more difficult problems, teachers can create situations to guide students to carry out research based learning and problem based learning activities. For the comprehensive problems and key problems, teachers can combine with Ausubel (D.P.Ausubel) theory, by explaining the concept of learning theory, and collective teaching method to do a comprehensive exposition of knowledge.

Evaluation Summary -- Feedback Information. Teaching evaluation can diagnose the teaching quality level, effect and defect; it can detect the teaching effect of the teachers, student's learning achievement; it can adjust the teaching behavior according to the feedback information. At the same time, the evaluation itself is a kind of teaching activity. Students in the form of group feedback to evaluate the results of the report. Taking a competitive mechanism to select a person from a group to report, so that fully mobilize the enthusiasm of students, and improve student's organizational ability and speech ability. Showing outstanding works, improve the student's self efficacy of outstanding works, and encourage other students to study hard, that will help to complete the next task of learning tasks. Evaluation summary and feedback is the driving force to promote the continuous improvement of student's intelligence. Through the continuous "report show -- question -- evaluation feedback", and combine with the teacher's timely guidance, so that learning throughout the teaching process, to form a high efficiency development cycle of the ecological chain. In addition, teachers can combine the three strategies of organizational strategy, refinement strategy and activity strategy. So that the knowledge in the student's brain to establish a meaningful coding. Students knowledge system structure will be more 
perfect, and student's understanding of knowledge will be more thorough, so that student will not easy to forget ${ }^{[10]}$.

According to the tower theory of DELL's experience, only the students after accumulating some specific knowledge, and understand the abstract representation of the real things, students can effectively participate in the more abstract teaching activities. Therefore, after students in the completion of the two links (detection result -- solve the problem and arrangement work -- internalized knowledge), they already have a certain experience base. And then participate in this link; they can break the teaching difficulties.

After class, the teacher encourages students to combine their own learning experience to put forward valuable suggestions. Through further optimization of teaching activities to promote students to better learning. You can also invite parents to participate, put forward suggestions, so that teachers, students and parents to form a closely interwoven network, and promote the efficient learning of students.

Flipped Classroom Teaching Model Based on "Guidance and Study Synchronous Double Helix" opens up the way of Flipped Classroom for teacher activities and student activities simultaneously. Five links constitute the five essential elements of Flipped Classroom Teaching Model Based on "Guidance and Study Synchronous Double Helix". The first pair of elements is the core of the other four pairs of elements. Second to carry out after the three elements to do the groundwork. After three pairs of elements are the most important, it is the key link of student's knowledge. Each pair of elements is closely related to each other, so that teachers and students activities closely twisted together. Between each pair of elements is all of one mind. Working hard for achieving the teaching goal together and meeting the needs of students.

\section{Application Consideration of Flipped Classroom}

It is only through constant adjustment and change that can realize its own development. Flipped classroom as a teaching model is no exception. In order to speed up the process of the educational revolution, the following suggestions are put forward in this paper:

Improve the Educator's Technique Ability. Micro video is an essential teaching resource for Flipped classroom. If educators make micro video as skilled as PPT, Word and other courseware, and effective use of cloud platform, mooch, big data learning analysis and other new technologies. It will be much easier for educators to carry out flipped classroom.

Resource Sharing. Resource sharing requires excellent educators to build a resource pool(or with the help of the existing network teaching resources), to expect learners to be able to gain the harvest and the knowledge at the same time. This process will inevitably relate to the issue of intellectual property rights. Therefore, it is necessary to improve the legal system.

Rational Orientation of Each Subject. When we carry out the flipped classroom, do not blindly abandon the traditional education. Rational orientating of each subject and then applying to the flipped classroom. Although flipped classroom teaching resources base on micro video, this does not mean that any subject is suitable for the use of micro video teaching. In the process of teaching, as long as the guide learning resources, a smart and effective guidance, can reasonable use of any form of teaching resources to guide students to learn (including text, sound, pictures, etc.).

Classroom Teaching Activity Design. Flipped classroom test teacher' s ability that reasonable control time, design efficient teaching activities (including dialogue, questions and discussion, etc.), with the change of students' learning effect in class. Teachers should be good at observation, teaching students in accordance with their aptitude, making students enable to maximize assimilate knowledge. Students eventually realize the absorption of knowledge. Teachers should deeply position their responsibilities: Before class, teacher is an instructor and helper hidden in the learning platform. In class, a teacher is a collection of many characters, including designer, organizers, guides, helpers and problem guides of learning style.

Improve Learner Autonomy. Motivation is the key to autonomous learning. The reason why backward students do not like to complete the task before class, it is because this task does not motivate them to learn. According to the previous design of autonomous learning task list, making clear about the 
purpose of study, layering the task, and attach a suggest method to the back of the task. So backward students can overcome the difficulties to complete the task. And students 'Self-efficacy and learning motivation can develop.

The rise of the flipped classroom makes the purpose of education more clear. The purpose of education is to help people to reap the fruits of life. The responsibility of education is to tap the potential of human being. The mission of education is to promote human dignity. It is a long process that people recognize the flipped classroom. As any educational revolution in history needs to use the time to baptize. What we can do is to speed up the process of flipped classroom education revolution.

\section{References}

[1] H.Wang, W.Zhao, L.H.Sun and H.X.Liu: Modern Educational Technology, Vol. 23 (2013) No.8, p5.(In Chinese)

[2] X.L.Zhong, S.Q.Song and L.Z.Jiao: Open Education Research, Vol. 19 (2013) No.1, p58.(In Chinese)

[3] L.Jin: Flipped Classroom and Micro-lectures Method of Teaching (Beijing Normal University press, China 2015).(In Chinese)

[4] W.X.Fan, Y.Ma, K.Li and B.F.Qui: Open Education Research, Vol. 21 (2015) No.3, p90.(In Chinese)

[5] Z.T.Zhu: Open Education Research, Vol. 22 (2016) No.1, p18. (In Chinese)

[6] P.Xu, Y.N.Wang, Y.H.Liu and H.Zhang: Journal of Distance Education, (2013) No.6, p11.(In Chinese)

[7] J.J.Bian and F.Y.Xu: China Educational Technology, (2016) No.2, p64. (In Chinese)

[8] Butzler and B.Kelly: The Effects of Motivation on Achievement and Satisfaction in a Flipped Classroom Learning Environment (Ph.D., Northcentral University, 2014).

[9] Miller and A.Kelly: Role of Pre-Course Student Characteristics on Student Learning in Interactive Teaching Environments (Ph.D., Harvard University, 2015).

A. Rania: Evaluating Tangible User Interface-based Mobile Learning (Ontario: University of Ottawa, 2013). 